\title{
Entrevista
}

\section{Entrevista com Rosilene Alvim e José Sérgio Leite Lopes}

Na última edição da Reunião Brasileira de Antropologia (RBA) de 20Io, o documentário Tecido Memória - dirigido por José Sérgio Leite Lopes, Rosilene Alvim e Celso Brandão - ganhou o VIII Prêmio Pierre Verger de Vídeos Etnográficos. Realizado a partir de pesquisas antropológicas e historiográficas produzidas durante a década de I970 e retomadas entre 2006 e 2008 , para o processo de filmagem, o documentário aborda a vida cotidiana, as lutas por direitos sociais e a memória dos trabalhadores das fábricas de tecido de Pernambuco.

Esta edição da Plural traz uma entrevista, realizada em maio de 20ıo, no Departamento de Sociologia da Universidade de São Paulo (USP), com os antropólogos Rosilene Alvim (IFCS-UFRJ) e José Sérgio Leite Lopes (Museu Nacional - UFRJ), diretores do vídeo etnográfico. Além de comentarem sobre o filme, os antropólogos relatam suas trajetórias, as pesquisas realizadas desde a década de 1970, a experiência como professores visitantes na Universidade Federal de Pernambuco (UFPE), entre 2002 e 2005, bem como alguns dos principais temas de suas pesquisas individuais: trabalhadores, família, conflitos sociais, juventude e esporte.

Revista Plural*: Primeiro, gostariamos que vocês falassem sobre suas trajetórias acadêmicas. Quais foram suas preocupaçōes e questōes iniciais?

Rosilene Alvim: Eu fiz mestrado e doutorado em psicologia internacional. Trabalhei primeiro com artesãos e, depois, com as ligas operárias nessa fábrica onde realizamos as filmagens. Sempre quando eu levava meu caderno de campo, eu lia o que escrevia, pensava que náo conseguiria mostrar o que eu estava vendo, sem pensar ainda em um

\footnotetext{
* Entrevistadores: Enrico Spaggiari, Gustavo Taniguti e Fábio Tsunoda.
} 
registro visual. Depois de fazer a pesquisa de doutorado na fábrica com operários, em Pernambuco, surgiu a possibilidade de fazer esse documentário. Isso depois de quase trinta anos de termos feito a tese de doutorado: eu sobre a família, e o José Sérgio sobre a relação entre política e a dominaçáo entre patrôes e trabalhadores. Assim, quando nós regressamos a Pernambuco como professores visitantes, em 2004 e 2005, retomamos o contato com várias pessoas que entrevistamos, as quais foram muito importantes para a tese. Eram nossos amigos; íamos a Pernambuco visitá-los. Mas um pessoal novo do sindicato estava muito preocupado em fazer um documentário sobre a cidade, porque uma das pessoas que lá morava náo conhecia a origem da cidade. Ela foi fundada a partir de uma fábrica com vila operária, que foi edificada ali em Paulista, ao lado de Recife; antes, pertencia a Olinda, depois, tornou-se independente. A inda desses trabalhadores para trabalhar nessa fábrica de tecidos aconteceu quando a cidade era muito pequena, no início da década de 1920, na época da seca. Os próprios filhos que as famílias mandavam começaram a buscá-los e, nisso, construíram uma vila operária enorme, com uns vinte mil operários nos anos 1940, o que é possível visualizar no filme. Nós começamos, então, a filmagem com Brandáo, o fotógrafo, porque a gente achava que tinha que ser uma coisa razoavelmente bonita, e não somente entrevistas. Tínhamos muitas entrevistas; nosso problema era com imagens. Em resumo, essa foi minha trajetória. Depois, eu comecei a trabalhar com juventude, criança e adolescente e não voltei mais ao Nordeste nesse período, a não ser quando fomos para o Departamento de Antropologia da Universidade Federal de Pernambuco (UFPE).

Revista Plural: Após as primeiras pesquisas, como foi a inserção nas instituiçōes de ensino? Rosilene Alvim: Na realidade, eu comecei na Fluminense, depois, eu pedi demissáo, porque houve um vão político lá. Isso em 1975. Depois, eu dei aulas na UFRJ e fiz concurso para professor assistente. Atualmente, eu estou aposentada, no Instituto de Filosofia e Ciências Sociais, na área de Antropologia. Lá eu fundei um centro: Núcleo de Pesquisa sobre a Infância e a Juventude, mas, com minha saída, a coisa meio que se desfez. Eu estou ligada a algumas pesquisas, mas não sou mais professora, não estou assumindo um cargo de ensino. Em 1990, nós passamos dois anos fazendo pós-doutorado na França.

José Sérgio: O pós-doutorado foi no Centro de Sociologia Europeia, o grupo do Bourdieu. O Centro de Educação e Cultura que era ligado ao Centro de Sociologia Europeia.

Revista Plural: Quais as motivaçôes e questôes que alimentaram essa pesquisa de Pernambuco?

José Sérgio: Fiz Economia; antes e depois, eu procurei as Ciências Sociais. Eu fiz meu mestrado e doutorado no recém-fundado Programa de Antropologia do Museu Nacional. Foi fundado em 1968, e eu entrei em 1970. A Rosilene já estava lá, apesar de ser mais jovem do que eu. Ela já estava fazendo trabalho de campo com os artesãos lá no Ceará. Eu acabei entrando 
em um grupo de pesquisa sobre essa área da plantation canavieira, a agroindústria em Pernambuco. Havia o Moacir Palmeira, professor que estava coordenando uma série de pesquisas nessa área. Alguns colegas foram fazer a dissertação nessa época e escolheram grupos ligados a essa problemática. Eu fiquei com alguns grupos de operários industriais das usinas de açúcar que ainda náo haviam sido estudados. Outros ficaram estudando pequenos camponeses na periferia das grandes plantaçóes; outros, os trabalhadores rurais dentro dos canaviais; e outros ainda, o sistema de mercado, os barracões, etc.

Rosilene Alvim: Vale constar ainda que minha pesquisa foi feita dentro do Programa de Pós-Graduação em Antropologia Social e financiada pela Fundação Ford.

José Sérgio: Toda a pesquisa inicial estava dentro da área de Desenvolvimento Regional Comparado, que começou com as pesquisas de mestrado e tinha esse projeto de pesquisa ao mesmo tempo, tanto nas áreas Centro-Oeste e Norte como nas fronteiras indígenas, onde Roberto Cardoso de Oliveira, Roberto DaMatta, Roque Laraia e outros estavam trabalhando e onde também trabalhava o David MayburyLewis, professor de Harvard, que, embora britânico, era parceiro de Roberto Cardoso. Portanto, tinha esse projeto de pesquisa que pegava inicialmente essa área da fronteira agrícola do Norte e Nordeste, pretendendo fazer uma pesquisa comparada sobre desenvolvimento regional, e tinha essa pesquisa no Ceará, que era coordenada pela Nelma Aguiar, quando ela fez a pesquisa dela sobre $\mathrm{o}$ artesanato na área do Cariri, em Juazeiro.
Revista Plural: Orientada também pelo Moacir Palmeira?

José Sérgio: Não, era a Nelma Aguiar, que foi depois para o IUPERJ, durante muito tempo, e hoje está na UFRJ, se não me engano. Ela tinha conhecimento no Ceará e iniciou uma pesquisa por lá. Ela era professora do Programa de Pós-Graduação do Museu Nacional. Rosilene fez pesquisa nessa área. A pesquisa do Moacir Palmeira era na zona açucareira de Pernambuco. Depois é que fomos fazer campo; eu e alguns colegas, como Afrânio Garcia e Beatriz Heredia. Em 1975, fizemos um projeto maior, incorporando mais gente, que se estendeu dessa área de Pernambuco para outras áreas, como Alagoas, Paraíba e Maranhão, e foram incluídas também as áreas urbanas. Nessa época, incluímos essa pesquisa sobre fábricas têxteis. No meu caso, eu tinha estudado operários em indústrias do açúcar. Também tem vila operária, mais isolada ainda, porque é no campo, em torno da usina.

Revista Plural: A pesquisa que inspirou o documentário é posterior a essa da usina? José Sérgio: Posterior à dissertação. O doutorado começou em 1977, no Museu Nacional, mas esse projeto de "Emprego e mudança social no Nordeste" tinha tido um financiamento enorme, o que ajudou a estabilizar o programa. Partimos para essas fábricas suburbanas, que tinham também um tipo de industrializaçáo concomitante ao das usinas no início do século XX e também tinham essa particularidade de ter aglomeraçóes habitacionais, vilas operárias, etc. Em geral, tinham. Mesmo essa cidade, Paulista, foi formada pela fábrica. 
Rosilene Alvim: Na minha pesquisa sobre artesãos, eles diziam que faziam artes, cordōes de ouro e oficinas. Eles falavam mal, mas, no caso de eles serem proprietários, admitiam que as famílias deles trabalhassem, muito com aquela ideia de família. Por isso que, quando eu fui fazer a pesquisa nesse outro projeto, eu preferi trabalhar com a família de operários. Era mais prático, porque eles estavam nas casas da vila operária; entáo, do ponto de vista material, era mais fácil encontrá-los.

José Sérgio: Uma coisa ela descobriu com os artesãos: tinha essa categoria da arte, da arte industrial, como uma coisa importante. No caso dos operários da usina de açúcar, eles também falavam em arte, os operários de manutenção. A usina tem um setor de manutençáo muito grande, porque precisa, na entressafra, reconstruir a usina toda, já que ela foi deteriorada. Entáo, tem um grupo de profissionais enorme, e essa categoria de arte era importante. Além disso, tinha essa coisa do domínio da administração da fábrica, que é maior, extravasa a produção propriamente dita e se transforma em um governo local. Estávamos interessados nisso, por isso nós desdobramos para a fábrica têxtil, que, apesar de náo ser plantation, uma agroindústria, tinha algumas características parecidas, de arregimentação de gente do campo, de formação de operários, controle territorial, poder político, poder de organizar a vida social, o lazer, o futebol, essas coisas todas. Fizemos isso entre 1976 e 1977. Ficamos três meses em cada um desses anos; depois, até 1983, fizemos outras idas. Defendemos as teses em 1985 e 1986 e, depois, fomos para esse pós-doutorado na França, de 1988 até 1990. Tinha essa modalidade de bolsa de pós-doc, uma espécie de estágio no exterior. E tínhamos também uma relação com esse grupo do Bourdieu, porque alguns de nós já tinham ido para lá. O Moacir Palmeira foi aluno do Bourdieu, fez doutorado na França e assistiu a seminários do Bourdieu. Ele fez uma tese sobre o debate da questáo agrária no Brasil: O Latifúndio e a Questão Agrária no Brasil, ou seja, o debate entre feudalismo e capitalismo no campo nos anos 1960 e nas décadas anteriores. Havia esse contato e, na época, na Antropologia, liam-se bastante os artigos iniciais do Bourdieu, que depois foram publicados na Economia dos Bens Simbólicos, além de alguns outros, tais como o Celibato e o Camponês, sobre a atitude em relaçáo ao tempo no campesinato, artigos principalmente sobre a Argélia ou o interior da França. Líamos essa produção classificada como a mais antropológica do Bourdieu. Eram investigadas sociedades camponesas nessas matérias. Também na tese do Moacir, que era sobre o debate intelectual, lia-se sobre o campo intelectual. Assim, tínhamos uma boa ideia sobre esse grupo em seu início, nos anos 1970, quando não se tinha toda essa fama do Bourdieu. Depois ele foi traduzido para o inglês e ficou mais conhecido. Ele foi traduzido no Brasil. O Brasil teve essa ligaçáo precoce com o Bourdieu por causa desses orientados por ele. O Moacir, apesar de não ter sido orientado, assistiu a seminários. Isso em 1966. Depois, o Sérgio Miceli foi aluno do Bourdieu nos anos 1970.

Revista Plural: O Afrânio Garcia também? José Sérgio: O Afrânio Garcia também. Ele foi nosso colega de doutorado. Ele foi para 
lá e fez pós-doc, depois ele fez concurso para a École des Hautes Études en Sciences Sociales e se tornou professor de lá nos anos 1990. Hoje, ele trabalha no Centro do Brasil Contemporâneo, que é um centro da École que lida com o Brasil, e também no Centro de Sociologia Europeia. Havia essa relaçáo com o grupo do Bourdieu. Havia alguns convênios, como vocês aqui também têm com o grupo de lá. Depois, nós fizemos o doutorado e continuamos as atividades em outros projetos; a Rosilene, mais na área de infância e adolescência. Eu também lá na França comecei a escrever sobre o futebol; o futebol relacionado com a fábrica têxtil. No filme tem uns cortes sobre o futebol dessa fábrica. Tanto nas usinas de açúcar quanto na fábrica têxtil havia os campeonatos internos das empresas. Então, eu consegui relacionar com esse fenômeno do futebol de empresas.

Revista Plural: Parece existir uma linha direta nitida entre as suas obras. Do seu livro $O$ Vapor do Diabo: O Trabalho dos Operários do Açucar! até o doutorado, passando pelo futebol, até o tema do meio ambiente, parece que está tudo ligado ao mestrado. Há uma continuidade e correspondência entre os trabalhos?

José Sérgio: Eu acho que o futebol já estava lá, embora eu não explorasse, pois era uma entre outras coisas. $\mathrm{O}$ meio ambiente estava lá, sobre as condiçôes de trabalho e outras coisas. Mas o meio ambiente veio depois, como temática mais política.

Rosilene Alvim: A Monique de SaintMartin, uma das pessoas da equipe do Bourdieu, que, na época, queria uma revista sobre futebol, queria um artigo. Eu falei que o Sérgio tinha um artigo sobre o Garrincha, e ele náo tinha. Quando o Garrincha morreu, ele ficou muito preocupado com a visão de que o Garrincha era um camponês no sertáo. Foi uma época em que meu pai morreu, eu vim para o Brasil e peguei o material para ele. Ele teve que escrever esse artigo correndo, e eu tinha certeza de que ele já tinha feito, porque, na época, ele ficou muito impressionado. Eu o joguei numa de que ele tinha que fazer. O Bourdieu e os editores ficaram interessados em publicar esse artigo sobre o Garrincha.

José Sérgio: Porque, às vezes, quando você está no exterior e em um grupo de pesquisa, você precisa adequar os temas que você trabalha à demanda da revista. A revista é temática. O tema do trabalho já tinha sido tratado em outros números da revista. $\mathrm{O}$ pessoal já estava preocupado com outras coisas. Eu tive que entrar por meio do futebol; introduzi esse futebol operário. E por aí entra o trabalho que eu tinha feito sobre fábrica, mas entrou por meio do futebol. Isso foi feito para essa revista no exterior. E outros artigos acabaram tendo interesse no exterior mais do que aqui dentro mesmo, porque o futebol brasileiro acaba sendo uma coisa atraente para as temáticas vistas do exterior.

Revista Plural: Recentemente, teve outra versão desse seu artigo lançada pela Revista Vibrant, vinte anos depois.

José Sérgio: Porque depois o artigo foi traduzido para alemáo, inglês, e a Vibrant pediu agora para publicar. Já o meio ambiente foi depois, nos anos 1990. Tem relação com a falsa questão do fim do 
trabalho ou do fim do proletariado, a crise da sociedade do trabalho. O meio ambiente aparece como uma temática importante de conflito. Tínhamos a possibilidade de fazer projetos. Na época, existia um departamento do meio ambiente no Banco Mundial que tinha um ex-professor nosso do programa de pós-graduação, que foi um orientado, Shelton Davis, que escreveu sobre a questão indígena no Brasil e fez também pesquisa na Guatemala. Nessa época, ele estava nessa área ambiental do Banco Mundial e estava interessado na questấo da poluiçáo industrial. Ele próprio tinha sido ativista em relação a um acidente nuclear na época, um desses grandes acidentes. Ele tinha interesse nisso, e pensamos em fazer com algumas pessoas que já tinham algumas entradas. Era sobre Volta Redonda, a siderúrgica que estava no contexto da privatizaçáo, onde a própria privatização da CSN tinha uma cláusula de compensaçáo ambiental pelo que a empresa fez de danos ao meio ambiente. A nova empresa privatizada se comprometia a assumir toda essa parte. Entáo, teve um conflito durante toda essa década de 1990 da populaçáo local com a siderúrgica em torno dessas questóes. Isso substituiu, sucedeu os conflitos de trabalho da década anterior, do sindicato, das greves, etc. Com a privatizaçấo, eles pararam com brigas dentro do sindicato, e houve um movimento em outra direção, mais de bairro e de questóes ambientais. Isso também polarizou na Justiça. Trabalhamos sobre isso e também sobre Angra dos Reis, que é o caso nuclear. O caso de Taboraí também, que era o posto de pescadores. Nos anos 2000, tivemos esse convite. Rosilene foi convidada pela Antropologia, por causa das questóes de juventude que eles estavam interessados em estudar, e eu fui de contrabando pela Sociologia. Nós pegamos a bolsa de professor visitante, demos aula e ficamos próximos dos nossos antigos entrevistados, que já estavam mais velhos, avós; alguns morrendo. Estávamos preocupados em registrar essa memória, e coincidiu com o interesse deles lá. Eles também sentiam isso. Rosilene Alvim: Porque Paulista, quando a gente fez a pesquisa, tinha 70 mil moradores no município. Essas famílias foram vendendo, e fizeram vários conjuntos habitacionais. Paulista se tornou uma cidade dormitório, pois as fábricas fecharam. Hoje, tem uns 300 mil habitantes. As pessoas que estấo lá são pessoas que, quando as empresas começaram a demitir os trabalhadores, tentaram fazer um acordo com a entrada do FGTS, e, nesse acordo, muitas pessoas fizeram com a casa e algum dinheiro. Então, as casas estão lá, a vila, mas nem tudo está lá. A fábrica eles venderam. O governo comprou uma parte, tem uma estrada que passa em cima de onde era a fábrica.

José Sérgio: Tem muitas ruínas.

Rosilene Alvim: Quando a gente fez a pesquisa náo existia muito isso. A fábrica estava morrendo, náo estava funcionando muito bem...

José Sérgio: Tinha ainda dois mil operários. Era uma fábrica grande.

Rosilene Alvim: Mas esses conflitos fizeram com que muitas pessoas permanecessem lá. Era um grupo muito histórico. A minha tese sobre as famílias operárias tem cinco capítulos sobre a história, como eles eram, filhos de camponeses, pescadores, artesãos, 
e se transformaram em operários e como isso gerou um tipo de família específica. Esse tipo de fábrica me proporcionou trabalhar sobre famílias operárias de pessoas que trabalhavam na fábrica, tanto criança quanto adultos. Dos seis capítulos, eu tenho um sobre as famílias, que eu chamei de "Famílias Contemporâneas". Eles iam sempre para a história deles.

Revista Plural: Qual a importância que os dados biográficos tiveram nas pesquisas sobre o Nordeste? E, quando vocês estavam preocupados com cultura popular e classe operária, quais foram as conexöes que vocês perceberam entre trabalho e a experiência urbana? Vocês deram algumas pistas de controle territorial dentro da fábrica...

José Sérgio: Grande parte da pesquisa antropológica e etnográfica está voltada para as entrevistas, embora tenha toda essa parte de inserção e de observação direta. Em grande parte, quando nós fizemos as entrevistas, estávamos na situação de doutorandos, pessoas mais jovens entrevistando pessoas mais velhas. Estavam em plena atividade ou até mesmo pessoas aposentadas. Entáo, um grupo social, muitas vezes, remete a essas pessoas para falar da história. São pessoas com conhecimento do lugar. Principalmente com esses mais velhos o pesquisador acaba fazendo a trajetória mais completa.

Rosilene Alvim: Porque isso é uma constante nas entrevistas. Você fazer uma pergunta, e a pessoa, que não tinha um pensamento sobre aquilo, começava a ir daqui para lá, falando de onde a família vem, a história, como as coisas iam se repetindo. Assim, fomos aprofundando também nessa direção. A parte urbana, como era uma coisa muito fechada lá, a gente não discutiu muito. É uma indústria, eles viviam em uma vila operária, tinha a parte rural em volta, que fornecia a alimentaçáo para vender na feira. Eu náo sei definir, é entre o urbano e o rural. Sáo categorias que não dão conta. José Sérgio: Era uma coisa sustentável, que não se pensava nisso. Eles fizeram um modelo sustentável meio que perverso. Até na época, se você pega a literatura de história econômica, Stanley Stein, um brasilianista que faz a história da indústria têxtil no Brasil, mostra que tem um conflito entre as indústrias emergentes, no Nordeste e no Sul também, e as do Rio de Janeiro e de São Paulo, que eram as dominantes. Nesse contexto, tinha uma competiçáo, porque as novas queriam importar fundos de máquinas, e as dominantes diziam que existia uma superprodução no Brasil. Então, náo podia importar mais máquinas, tinha que controlar a produçáo no país, tinha uma superproduçáo, não se vendia, e tinha uma tremenda crise. Então, tinha uma briga. O pessoal do Sul, dominante, acusava o pessoal do Nordeste, principalmente essa fábrica de Paulista.

Rosilene Alvim: Porque havia outras fábricas...

José Sérgio: No filme procuramos ver o conjunto delas, mas acabamos filmando duas: a de Paulista e outra que também estava funcionando. E filmamos dentro da fábrica, em Escada, perto de Recife. O pessoal de Sáo Paulo se queixava que o pessoal do Nordeste ganhava a concorrência, muitas vezes, colocando preços menores, com tecidos mais baratos, porque o pessoal 
de lá vivia em um regime feudal, quer dizer, os operários no Nordeste ganhavam muito menos, então, eles tinham salários mais baixos e fiscalização trabalhista menor. Isso contribuía para ter um custo menor e vender por menos. Na verdade, eles tinham lá esse sistema que era diferente e interessante para nós antropólogos: você ter no mesmo grupo social, na mesma geração, pessoas que vieram do campo, imersas nas relaçóes camponesas ou canavieiras e, ao mesmo tempo, transformaram-se em operários. Isso tudo no decorrer de uma geração ou no máximo de duas ou três geraçóes. Gente que viveu essa experiência. E, ao mesmo tempo, tinha esse sistema de pegar pessoas no interior, principalmente jovens, para trabalhar, e até mesmo crianças. Os jovens eram o principal alvo. Já os velhos, os pais de família, têm um passado camponês muito forte. Para manter o pessoal lá, eles também cediam terrenos para a pessoa plantar. Ao mesmo tempo, eles tinham necessidade de lenhas para mover as máquinas, então, eles compraram os engenhos que produziam cana, interessados nas máquinas de esteira, liberando os camponeses e trabalhadores rurais de trabalhar na cana e produzir na subsistência para fornecer para a feira, com o preço que a fábrica administrava. Então, eles pagavam baixos salários, mais baixos que em Recife, mas o custo de vida era bom, e a alimentaçáo, a casa, tinha tudo para se sustentar. Entáo, era uma coisa integrada do campo e da cidade, mas que com o tempo vai se tornando cada vez mais urbano.

Revista Plural: A questão migratória passa pela experiência dos trabalhadores?
José Sérgio: Sim, principalmente pela família. Os pais são camponeses, aquele pessoal filho de camponês, com uma ligaçáo com o campo. Em Pernambuco, o movimento social muito forte é pelo lado do campo. Em 1964, as Ligas Camponesas estavam em voga, era recorrente.

Revista Plural: Isso aparece nas entrevistas... José Sérgio: Sim.

Rosilene Alvim: Eles têm sua própria identidade.

Revista Plural: Questöes também trabalhadas no livro Um Nordeste em Sáo Paulo, de Paulo Fontes. Isso aparece nas entrevistas, pessoas que têm a experiência de ter vindo de outro lugar e dizer que vieram de outro lugar...

José Sérgio: Isso, o livro do Paulo Fontes sobre migraçáo aqui em São Paulo. Isso é interessante, porque, aqui em São Paulo, na época, na literatura sociológica, você tinha os trabalhadores de origem rural e os trabalhadores que já estavam em Sáo Paulo e eram mais qualificados. Tinha um corte. E lá víamos aquilo acontecendo lá mesmo. Rosilene Alvim: E aprende a trabalhar, a se especializar. Muitos vieram para Sáo Paulo trabalhar como operários depois em fábricas têxteis.

José Sérgio: Depois também em metalúrgica...

Rosilene Alvim: E eles não ficaram somente no mesmo ramo. O teceláo só podia trabalhar em tecelagem, mas os que dominavam outra área ocuparam vários lugares, tendo aprendido o trabalho nessa fábrica.

José Sérgio: O fluxo migratório se inverte em Paulista. De 1990 a 2000, já é uma 
migração de Recife para Paulista, da cidade para o subúrbio, para esses conjuntos habitacionais. Então, aquela história anterior é esquecida. Essas transformaçóes levaram esse pessoal mais antigo a ter essa demanda por memória, de fazer valer como foi sua geração, quais foram as lutas locais. Foi isso que encontramos lá...

Rosilene Alvim: Principalmente porque o sindicato é um sindicato de aposentados. Você só vê funcionando lá agora, no caso de Paulista, a Santista e algumas outras pequenas fábricas.

José Sérgio: Porque lá teve essa fábrica de Paulista, e, em 1968, fizeram um distrito industrial, depois eles venderam essas terras, e foi feito um incentivo fiscal pela Sudene. Entáo, tinha Hering, Santista, General Eletric. Mas, dos anos 1990 para 2000, com a crise, essas filiais começaram a fechar. Esse distrito industrial teve várias fábricas fechadas, comprometendo a regiáo. E, entre os operários do sindicato hoje, poucos chegaram a trabalhar na fábrica antiga. É uma geraçáo que se formou nessas fábricas de filiais. Eles fizeram oposição sindical nos anos 1980, mas sempre vivendo com as geraçôes anteriores, e acabaram promovendo essa questão da memória, assim como os mais antigos. Entáo, coincidiu que alguns personagens mais ligados a nós na pesquisa eram também testemunhas dessa história. Agora, ao filmá-los, conseguimos fixar isso de alguma maneira. Alguns já tinham morrido, e aí filmamos isso. As primeiras filmagens foram com Celso Brandão, porque não tínhamos nenhuma experiência com filmagem. Com essas máquinas mais digitais e domésticas, come- çamos a nos aventurar a filmar entrevistas, mas precisávamos do cineasta para filmar, dar instruçóes. Fizemos essas filmagens em 2006. Voltamos porque vimos que faltava material e começamos a fazer uma grande pesquisa de imagens no Arquivo Nacional, na Biblioteca Nacional, na Cinemateca de São Paulo, na Fundação Joaquim Nabuco. Tínhamos fotos de lugares íntimos do nosso tempo de pesquisa. Tiramos fotos em 1967, mas o pessoal tinha desconfiança; por causa da Ditadura, não podia gravar. Não pensávamos em filmar nada. Quando paramos para pensar que o Bourdieu fotografou muito na Argélia nos anos 1950, percebemos que poderíamos ter feito alguma coisa assim.

Revista Plural: A partir da década de 1990, principalmente, começaram a ser realizadas no Brasil muitas pesquisas ligadas à Sociologia e à Antropologia visual. Quais são os desafios dessa metodologia?

José Sérgio: Hoje pensamos em fazer alguma coisa com isso. Tem também o documentário internacional e brasileiro Cabra Marcado para Morrer, Peóes. Eles estavam na nossa cabeça. Tinha uma problemática parecida. Em Peöes, Eduardo Coutinho foi lá e perguntou sobre o sindicato e os trabalhadores, a história de vida, a questão sobre a memória, comparar o momento passado com o hoje. Era nosso caso também. O pessoal hoje falando desse passado e como fazer isso. Contratamos também um pessoal para a montagem, que é de uma geraçáo mais nova, da geraçáo de vocês. Um pessoal que domina essas técnicas de montagem digital. Ficamos de 2007 a 2008 fazendo 
essa montagem, porque, ao mesmo tempo, a gente conhecia o material, a história, e elas, por outro lado, têm essa linguagem visual. $\mathrm{O}$ pessoal não era nem da área de Ciências Sociais, era de Cinema. Ao mesmo tempo, ajudaram nessa parte de sequência, de imagem...

Revista Plural: E como é construir uma narrativa de uma história no video? É semelhante à da escrita?

José Sérgio: Escrevendo, temos outros recursos. Analisa, conduz, interpreta, pode fazer nota de pé de página, faz uma comparação com outros países, generaliza, citam-se os clássicos, fala-se do processo de proletarização, etc. No filme, nossa opção foi montar o quebra-cabeça a partir das falas. Só colocamos no início uns três ou quatro letreiros para explicar ao telespectador do que se trata: uma empresa têxtil em determinado lugar do Brasil. O mínimo. E aí entra na fala deles. É outro tipo de exercício, mas na tese também fazemos isso.

Rosilene Alvim: Colocamos tudo o que os entrevistados acham importante...

José Sérgio: Na escrita temos que relacionar com a literatura anterior.

Rosilene Alvim: No filme tivemos um problema de náo ter imagem. Tivemos que desenvolver o filme que originalmente não tínhamos pensado. Hoje, encontramos as imagens sobre aquilo que os trabalhadores falavam. Mostramos, por exemplo, a greve de São Bernardo. O pessoal do filme Linha de Montagem cedeu.

José Sérgio: Começamos com as fotos que tínhamos de 1977, comparando com hoje. Tinha esse visual, tinha também algumas fotos históricas. Mas, depois dos relatos dos operários, descobrimos que Getúlio Vargas fora à cidade nos anos 1930 e 1940. Começamos a pesquisar se tinha algum material sobre essa época. Deparamo-nos com esses filmes para cinema. Isso estava na Cinemateca Brasileira. Eles recuperaram esse filme, e nós passamos. Nós tínhamos essa conjuntura do Getúlio Vargas, das leis trabalhistas, de Getúlio em Pernambuco. Conseguimos também fotos do Correio da Manhã no Arquivo Nacional. Tem muita coisa. Isso estava contextualizado. Uma possibilidade era essa, o período dos anos 1970. As próprias moças cineastas, que trabalham com montagem, conheciam os arquivos sobre a repressão e a ditadura do acervo da TV Tupi. Tinha a prisão do Miguel Arraes, do Gregório Bezerra. Tinha imagens sobre aquilo que acontecia com eles lá também, as prisóes, etc. Fomos conseguindo esse material fílmico. Depois achamos um comício do João Goulart com os camponeses. Vai criando um clima da época. Lá tem também esses movimentos contra as demissóes e o movimento de Igreja, comunidades de base, de luta pela moradia e pela vila operária, que sucedem os comunistas que tinham antes. Acabou que mostramos os movimentos daqui de Sáo Paulo e dos trabalhadores rurais do Nordeste. Mas é outra linguagem, e a gente teve que aprender mesmo, principalmente trabalhar em colaboração. Isso é uma coisa que saiu. Não entrou muita filmagem sobre a cidade.

Rosilene Alvim: Porque, se você tem a pretensáo de fazer um filme mesmo, é outra coisa. Fomos pegando aquilo que já 
tínhamos feito e tentamos narrar aquela história. É um pouco diferente. Não basta saber teoria antropológica. É diferente você trabalhar com imagem. Ela não vai só falar. Ela precisa ter um movimento fílmico diferente da escrita. O que tem por trás é o olhar do autor. É outra disciplina a Antropologia visual; você tem todo esse aprendizado técnico.

Revista Plural: A proposta de filmar tem uma potencialidade, mas, ao mesmo tempo em que se está filmando, não se está observando...

José Sérgio: É uma dificuldade, porque você fica muito preocupado com a técnica. Mas a gente tem também muita dificuldade e um vício de antropólogo de querer observar e acaba deixando de lado o registro e toda a técnica. Vocês vão ver no filme: aparecem os microfones que a gente usou. Vocês vão ver como a coisa mudou. Primeiro, tem um microfone de mão, desses de assembleia, teve uns problemas de microfonia. Depois, colocamos aquele de plástico na camisa, e tiveram outros problemas. Finalmente conseguimos um de lapela bom, decente... Rosilene Alvim: Quando está entrevistando, depois, quando vai montar, você tem que dar uns espaços entre sua pergunta e as respostas, porque senão na montagem come um pouco da fala. Uma série de macetes... José Sérgio: Não fizemos controle de som antes. A gente não tinha um técnico de som. Tinha o Celso, o cineasta. Não tinha uma equipe gigante. O Celso é documentarista e faz as coisas mais assim improvisadas.
Mas depois tivemos que pagar um técnico e engenheiro de audiovisual para dar uma uniformizada e inclusive recuperar alguns trechos que deu microfonia. Eram coisas-chave que estavam sendo ditas e no momento tinham ruídos de fundo: ar condicionado, buzinas de carro, etc., bem na hora da entrevista. Mas finalmente conseguimos, através dessas técnicas de limpeza de som. Deu para aproveitar, porque senáo teríamos que filmar novamente...

Revista Plural: Essa releitura por um novo tipo de linguagem é interessante...

José Sérgio: O bom para a gente é que conhecíamos as pessoas e suas histórias. Tínhamos muita coisa para perguntar sobre o que tinha acontecido de lá para cá, com eles, seus filhos, netos, etc. Observávamos a transformação. Aquelas pessoas eram íntimas nossas. Então, quando entrevistávamos de novo, a pessoa dizia: "Você já sabe disso, eu já te falei tantas vezes". A câmera introduziu outra formalidade, e a pessoa conta tudo de novo. Às vezes, a gente já sabia que aquela pessoa tinha falado muito bem no passado certas coisas, mas hoje ela não se lembra mais e náo fala da mesma forma. Mas conseguimos outros personagens novos, que não eram da pesquisa original.

Rosilene Alvim: Se tivéssemos dinheiro, poderíamos pegar as falas das pessoas que morreram - porque a gente tinha gravadas - e mostrar com fotos. Mas tínhamos muita dificuldade...

José Sérgio: É um desafio... 